\title{
$\mathbf{a}$
}

\section{Molecular function}

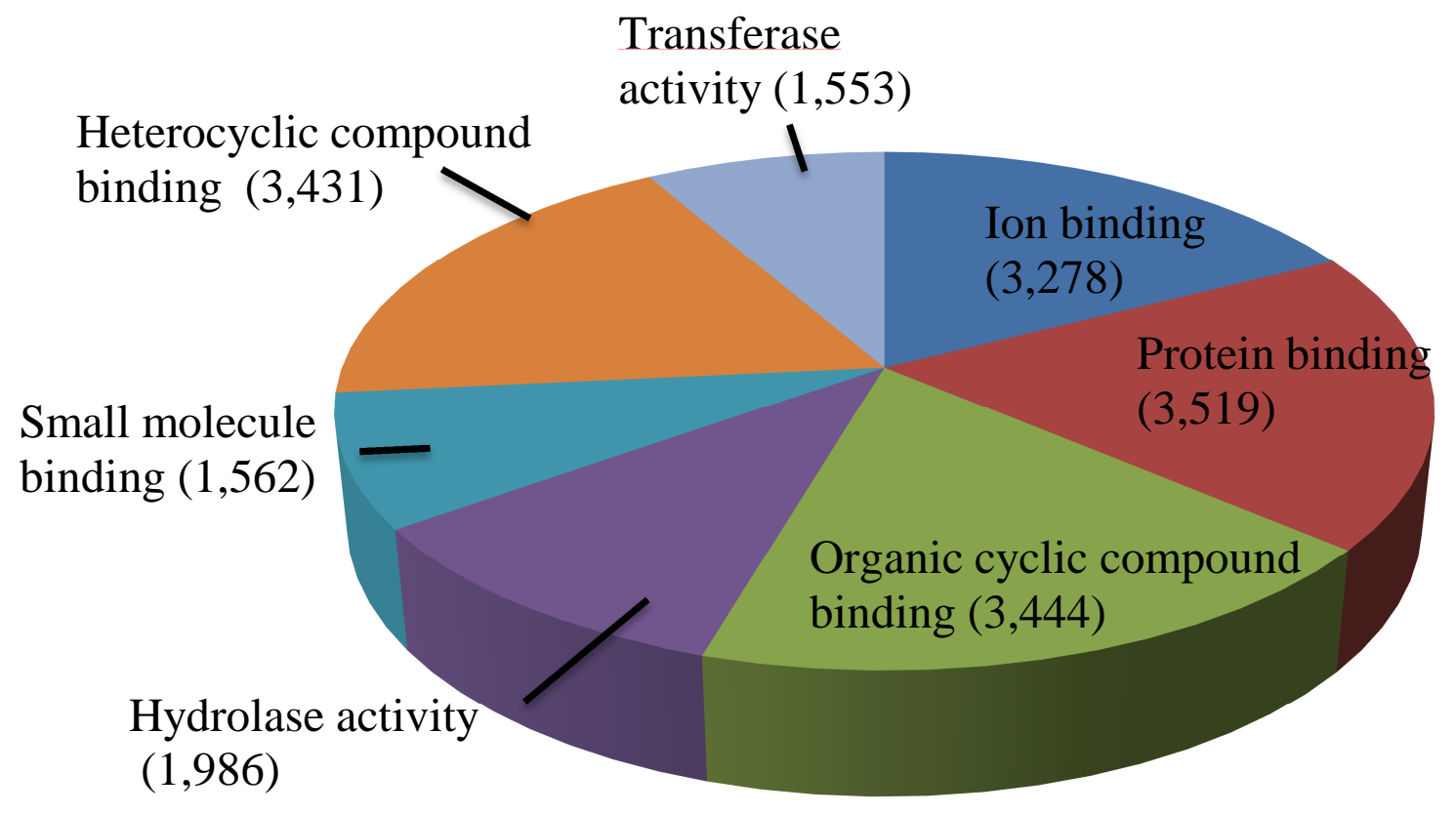

b

Cellular component

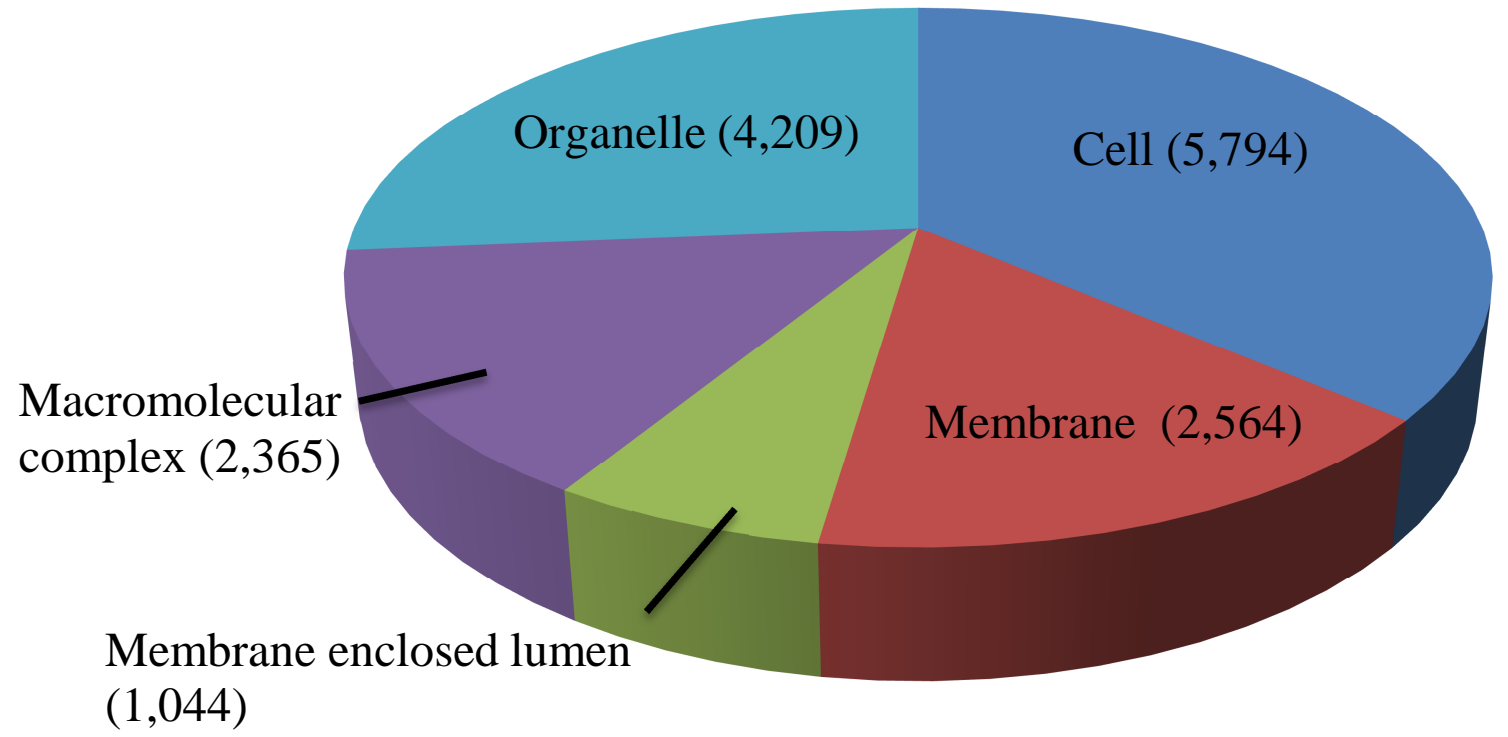




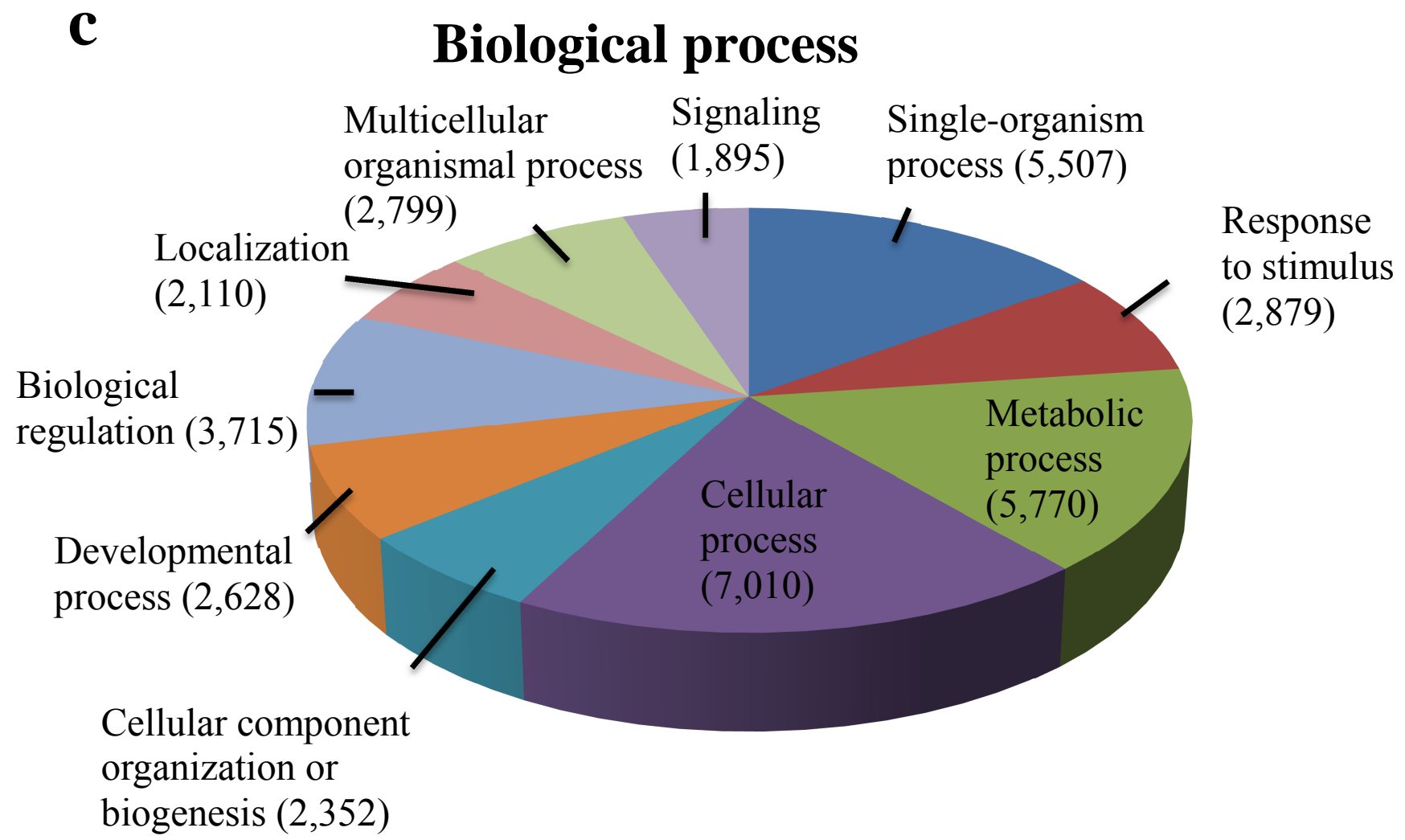

